\title{
The Perception of the Educational Philosophy in the Industrial Age 4.0 and the Educational Philosophy Productivity of Teacher Candidates
}

\author{
Yavuz Bolat ${ }^{1, *} \&$ Muhammed Baş ${ }^{1}$ \\ ${ }^{1}$ Faculty of Education, Mustafa Kemal University, Hatay, Turkey \\ "Correspondence: Department of Curriculum and Instruction, Faculty of Education, Mustafa Kemal University, \\ Hatay, Turkey. E-mail: yavuzbolat06@gmail.com
}

Received: June 3, 2018

Accepted: June 20, 2018 Online Published: June 25, 2018

doi:10.5430/wje.v8n3p149

URL: https://doi.org/10.5430/wje.v8n3p149

\begin{abstract}
While philosophy has confronted us as a concept that has taken place in every age of the thinking adventure of the humankind, philosophical considerations have been influential on all elements of human creation. One of these influence areas is education studies. Education has been influenced by the philosophy of education, which has occurred more specifically than philosophy. Educational leaders and pre-service teachers should notice the availability of using this influence and the educational philosophy as a tool. This research was conducted in order to determine the perception of educational philosophy in the industrial age 4.0 and to find the educational philosophy productivity of pre-service teachers. The study group includes 111 pre-service teachers who take the training philosophy course in the 2nd class level in the Faculty of Education of Mustafa Kemal University in Turkey. 72 of these pre-service teachers are female, and 39 are male. This research where quantitative and qualitative data are used together is a mixed educational research. In the study, a 25-question test developed by the researcher and a semi-structured interview form consisting of 3 questions has been used to collect data. While the pre-test and post-test studies were conducted with the test which is the data collection tool, the data were analyzed by using the descriptive analysis and the content analysis of the data obtained from the interview form. When the findings of the study were taken into consideration, it was found that there was a significant difference between pre-test scores and post-test scores of the pre-service teachers participating in the research. The teaching process of the training philosophy course given has been found to be successful. It has been concluded that pre-service teachers have expressed the philosophy and education relationship with human-based views. It has been found that pre-service teachers prefer the "progressive training philosophy" if they want to make a new educational design. However, it has been determined that pre-service teachers did not have an idea about technology and technological developments in the industrial age 4.0 .
\end{abstract}

Keywords: philosophy, philosophy of education, industry 4.0, teacher training, productivity

\section{Introduction}

\subsection{Education and Philosophy}

The human's try to understand its environment, nature, object and its external beings has revealed the process of asking questions and seeking answers to these questions. Philosophy was born as the major product of this process Philosophy has become an indispensable element of mankind in maintaining its existence in the course of the birth and development of modern sciences.

Ergün (2015) defines philosophy as love of wisdom, but also expresses that human always longing for understanding the truth. This longing for knowledge has made it possible for a human in search to develop generally a mind-based perspective to learn the truth. This situation has naturally made it a human-based activity and the main product of the human mind.

In the historical process, it appears that even the most primitive societies have an educational activity. There occur differences in the level of development according to the current state of these activities, social expectations, and socio-cultural structure. However, societies have always sought a better education in order to better bring up future 
generations. This search provided the foundations of the relationship between education and philosophy.

The education-philosophy relationship describes an active relationship, not a static one, despite some changes in the historical process. The idea that education alone may be sufficient for human development has started the process of separation from philosophy. However, during the studies of separation and independence from philosophy, the education, which is seen as experiential research (Locke, Rousseau), experiential anthropology (Kant), experiential psychology (Trapp), has returned back to practical philosophy (morality) and philosophy of history for some time (Ergün, 2015). Today, the education-philosophy relationship has turned into an indispensable relation and become a philosophical area in the form of the educational philosophy. One of the foundations of program development in education is the philosophical foundations of the education. This foundation is explained by the philosophy of education. When it is considered for the generality of education, the philosophy of education is directed towards a thoroughly detailed interaction with all educational policies (Schouten \& Brighouse, 2015).

Researchers engaged in practical or theoretical studies on subject areas of educational philosophy understand and explain the philosophy of education different from each other (Bim-Bad \& Egorova, 2016). Educational philosophy produces considerations on education in a more specific field than general philosophy. Educational philosophy generally relates to philosophy by teaching methods in specific meaning (Moore, 2010). In other words, it studies the philosophical problems in education. From this point of view, educational philosophy can be defined as the research of the aims of attitudes and behaviors expected to be developed by students through formal schooling (Tuncel, 2004). Educational philosophy contributes to the dimensions of identifying systems' goals, planning learning-teaching processes, realizing teaching, selecting teaching strategies in class, and measuring and evaluating (Wiles \& Bondi, 2011). The contribution of philosophy in general, of educational philosophy in particular, to objectives, curriculum, teaching process and institutional management is clear (Erkılıç \& Himmetoğlu, 2015).

Philosophy examines the general and fundamental problems related to existence, knowledge, truth, beauty, law, justice, ethics, aesthetics, profession, personal development, reason, and language and finds answers in the context of its own methods (Dash, 2015; Krillov, Fadeeva \& Fadeev, 2016). Educational philosophy plays a determining role in the analysis of educational objectives, the identification of the human upbringing model, the determination of the appropriate content for this model, the design of the teaching process, the design of the educational institutions, and the determination of the learning periods. Training philosophy seeks answers to some questions while providing this effect. These are:

$\checkmark$ What is the meaning of education in terms of individual and society?

$\checkmark$ What kind of human model should be brought up in the education-teaching process?

$\checkmark \quad$ Will the distant objectives of the education be successful at the end of the process?

$\checkmark \quad$ Are the educational objectives realistic?

$\checkmark \quad$ Is the content being taught valuable to the individual, society, and future?

$\checkmark$ How should the learning-teaching processes be designed?

$\checkmark$ Do learning-teaching processes serve the objective?

$\checkmark \quad$ What is the expectation of society about education? Will the education be able to realize this?

$\checkmark$ Which school model can achieve success in education?

$\checkmark$ Are school structures appropriate for the process?

$\checkmark$ Does the education serve social development?

$\checkmark \quad$ Is the education successful in transferring culture and development of culture?

$\checkmark$ Do the educators contribute to the individual and the society in the education process?

Above are given some questions of the educational philosophy seeking answers on education. This questioning and answer-seeking process will undoubtedly contribute to the development of an educational system. The different answers given to these questions constitute different educational philosophical views (Tuncel, 2004). The following are the considerations related to educational objectives and methods that the main educational philosophies argue. 
Table 1. Educational Philosophical trends and General Properties

\begin{tabular}{|c|c|}
\hline Educational Philosophy & General Properties \\
\hline \multirow{7}{*}{ Perennialism } & There are absolute truths that do not change in life. \\
\hline & Education brings up the individual according to ideal and universal truths. \\
\hline & $\begin{array}{l}\text { Educational programs are structured through sociology, literature, mathematics, } \\
\text { philosophy, logic, language, natural sciences, and classics. }\end{array}$ \\
\hline & $\begin{array}{l}\text { The information contained in the content of the program is absolute and certain } \\
\text { information. }\end{array}$ \\
\hline & In the context of teacher authority, penalties are applied when necessary. \\
\hline & They are passive receivers who are led by their teachers. \\
\hline & The teacher is at the center of the educational environment. \\
\hline \multirow{6}{*}{ Essentialism } & The basic culture that constitutes society has a common essence. \\
\hline & The cultural transfer is carried out in order to ensure social cohesion in society. \\
\hline & $\begin{array}{l}\text { Educational programs provide basic living skills, social cohesion, and academic } \\
\text { achievement. }\end{array}$ \\
\hline & The content is made up of the subjects in which culture and values are transferred. \\
\hline & Prize and penalty are used in the school system and the classroom environment. \\
\hline & $\begin{array}{l}\text { As the teacher is at the center of the educational environment, the student memorizes } \\
\text { those that are transferred to him/her, and answers when asked. }\end{array}$ \\
\hline \multirow{8}{*}{ Progressivism } & Change is an inevitable reality. \\
\hline & The education should prepare the student for the change actively. \\
\hline & There exist problems related to the life in the program. \\
\hline & The information is not absolute. It is changeable or falsifiable. \\
\hline & Scientific thinking is used in the active and collaborative learning process. \\
\hline & The teacher is a guiding person. \\
\hline & Student-centered learning-teaching processes are used. \\
\hline & $\begin{array}{l}\text { Evaluation of the processes realized by the individuals who produce solutions to the } \\
\text { problem is performed. }\end{array}$ \\
\hline \multirow{8}{*}{ Reconstructionism } & The school should be a solution to the cultural crisis. \\
\hline & The main purpose of the education is the reconstruction of culture and society. \\
\hline & $\begin{array}{l}\text { Since knowledge is not certain, the individual should be brought up with this } \\
\text { consciousness. }\end{array}$ \\
\hline & Using the scientific methods, critical thinking and problem-solving are important. \\
\hline & The classroom environment must be democratic, no punishment should be given. \\
\hline & The learner is valuable with all its properties. \\
\hline & In the educational environment, the whole culture of society must be represented. \\
\hline & $\begin{array}{l}\text { The student is assessed through versatile and multivariate measurement and } \\
\text { evaluation activities related to the process and the product. }\end{array}$ \\
\hline
\end{tabular}

\subsection{0 Industrial Age}

Ever since human began to apply knowledge to social life, it continues to develop with technology and technological products. The technological products brought about by this development have been the foundations of the industrial 
revolution. Looking at the history of the industrial revolution, significant developments have been achieved at the point reached to the fourth industrial revolution.

\subsubsection{The First Industrial Revolution}

The First Industrial Revolution (1760-1830) began to show its effectiveness through the mechanization of weaving looms in England. However, this process was not limited to England, but spread to Europe. In this period between the 18th and 19th centuries, this is often referred to as the Mechanization Age, onset of using steam as well as coal as a source of energy thanks to new inventions also played an important role in the spread of the machines. As a result of using pit coal and steam instead of wood in the production area, increasing the power of movement provided mechanization and transport of products to the factories. Traditional family companies and small manufacturing facilities have given their places to large factories. The increase in production in the factories led to the search for Market areas and the creation of new markets.

\subsubsection{The Second Industrial Revolution}

While the First Industrial Revolution represents the power of steam and coal, steel, electricity, petroleum and chemical materials were started to be used in the production process as well as steam, coal, and iron in the Second Industrial Revolution. In the early 20th century, the invention of the petrol-fueled internal combustion engines led to the foundations of a non-irreversible development for production. Now, there is a big increase in production items and their amounts, urbanization are accelerating as the population of cities increases. The reduction of communication barriers between people with telephones and telegraphy has accelerated the access to information and products.

\subsubsection{The Third Industrial Revolution}

While the First Industrial Revolution is defined as the mechanization of production and the Second Industrial Revolution as the acceleration of production, the Third Industrial Revolution is defined as the automation and digitization of production. After the 1970s, the development of electronic, information and communication technologies led to moving of programmable logic controllers (PLC) into advanced automation in production, providing the automation of production (digitization). During this period, the productions of areas such as a computer, nanotechnology, fiber optics, laser, nuclear, bio-agriculture and biogenetics have become an economic value. In the First and Second Industrial Revolution, the overuse of energy resources and the destruction of nature have led to the idea of the use of renewable energy resources in the Third Industrial Revolution. The third industrial revolution, which started in the 1970s and contained a high level of automation based on electronic and information technologies, has grounded the next phase, the Fourth Industrial Revolution (Stock \& Seliger, 2016).

\subsubsection{The Fourth Industrial Revolution (4.0 Industry)}

Industry 4.0 or 4th Industrial Revolution terms were first used in 2011 at the Hannover Fair in Germany (EDV, 2017). Apart from automation-based production of technological or electronic products in the Third Industrial Revolution, the Fourth Industrial Revolution can also be regarded as a clever factory system in which cyber-physical systems monitor the physical processes of factories and make decisions. The basic communication and workflow of these systems require communication between the machines. Instead of just producing electronic devices, the idea of producing intelligent production areas and that these products work automatically or synchronously with other devices have emerged. In other words, the system should be able to make simple decisions and be autonomous as much as possible. Driverless cars, unmanned aerial vehicles, active security systems, systems capable of producing probing solutions, intelligent habitat technologies are the products of the Fourth Industrial Revolution based on artificial intelligence. Schwab (2016) sees the Fourth Industrial Revolution not only as an update, but also as a rate of change that cannot be avoided, wide enough to affect every line of business in almost every country and being powerful as a precursor of changes in the systems of production, management, and control. The building blocks or the triggering elements of Industry 4.0 are listed as follows (Eldem, 2017):

1. Internet of Things, IoT

2. Simulation

3. Autonomous Robots

4. Additive Manufacturing

5. Augmented Reality

6. Cloud Computing 


\section{Cyber Security}

8. Big Data and Analytics

9. Horizontal and Vertical System Integration

In brief, steam-powered machines started to be used at the end of the 18th century; mass production happened to be possible with electrical energy at the beginning of the 20th century, and since the 1970s, automation in the industry with electronics and information technology became widespread. Today, we are taking steps of transition to the fourth phase of the industrial revolution to which the value chains are connected end to end by cyber-physical systems and dynamic data processing (TÜSİAD, 2016). The basic element of this transition is the artificial intelligence that will dominate the system or systems. The concept of the Internet of Things has emerged at this point because the artificial intelligence requires the connection and transfer of information among machines. The concept of the Internet of Things (IoT) refers to that data can be collected, processed, transformed into new information, reproduced, and organized from different sources found in a workplace, workshop or factory (Kopetz, 2011). This leads to cyber-physical machines that think, plan, work, and make decisions on their own. Robot technologies will be the most important products of this process.

While these factors lead to rapid changes in the area of information and technology production, the changes that are experienced cause the change of education systems. The perception of this change, the goals of education, and the new generations to adopt this idea requires that the philosophy of education has a viewpoint that can perceive a change. In the Industrial Age 4.0, the philosophy of education should be able to lead the developments rather than it should adapt to these developments. For this reason, this research was conducted to identify the perception of educational philosophy in the industrial age 4.0 and to determine the educational philosophy productivity of pre-service teachers. To identify the perception of the educational philosophy in the Industrial Age 4.0 and to determine the educational philosophy of pre-service teachers:

1. To control the success of teaching process of training philosophy course,

2. To determine how pre-service teachers, explain the relationship between education and philosophy,

3. To determine what kind of benefits, do the education and philosophy relationship have according to the pre-service teachers,

4. To try to identify which educational philosophical trend pre-service teachers tend to choose if they want to make a new educational reform as an educational designer.

\section{Method}

This research was conducted in order to determine the perception of educational philosophy in the industrial age 4.0 and to find the educational philosophy productivity of pre-service teachers. This research where quantitative and qualitative data are used together is a mixed educational research. Mixed method types of research are those in which data processing is performed by combining qualitative and quantitative methods in a study or a series of consecutive studies (Creswell, 2003). Since the analysis of data collection tools applied to the target population in this research requires a mixed research approach, the research is an education research with the mixed methodology.

\subsection{Study Group}

The study group includes 111 teacher candidates who take the education philosophy course in the 2nd class level in Faculty of Education of Mustafa Kemal University in Turkey. Information on these teacher candidates is given in Table 2.

Table 2. Participants

\begin{tabular}{cccccc}
\hline Class & Female & $\%$ & Male & $\%$ & Total \\
\hline 2 th & 72 & 55.80 & 39 & 44.20 & 111 \\
\hline
\end{tabular}

A total of 111 teacher candidates participated in the study at the second-class level according to Table 2.72 of the teacher candidates participating in the study were female $(55.80 \%)$ and $39(44.20 \%)$ were male.

\subsection{Data Collection Tool and Data Analysis}

In the study, a 25-question test developed by the researcher and a semi-structured question form consisting of 3 questions has been used to collect data. While the pre-test and post-test studies were conducted with the test which is 
the data collection tool, the data were analyzed by using the descriptive analysis and the content analysis of the data obtained from the interview form.

The first of the data collection tools, the 25-question Educational Philosophy Course Learning Outcome Evaluation Test (EPCLOET), was applied to the 2nd year students who took the training philosophy course at the beginning of 2017-2018 Spring Semesters. After teaching an eight-week course content, the same test was applied to the students a second time, and then the students were asked to answer the semi-structured question form. Statistical analysis of data collected from EPCLOET was made using SPSS 16 package program. An independent-sample t-test was conducted to compare the pre-test and post-test scores of the students in the study group within themselves, and percent, frequency and standard deviation calculations were made. The subject areas of the questions constituting the EPCLOET have been given in Table 3.

Table 3. Educational Philosophy Course Learning Outcome Evaluation Test (EPCLOET) Subjects and Question Numbers

\begin{tabular}{llc}
\hline & Subjects & Number of questions \\
\hline 1 & Philosophy, philosophy of science and education & 3 \\
2 & A scientific view of education & 2 \\
3 & The purpose and subject areas of the educational philosophy & 2 \\
4 & Educational philosophy in education and teaching objectives & 3 \\
5 & Community, social and cultural functions of education & 3 \\
6 & Philosophical trends & 4 \\
7 & Education philosophical trends & 5 \\
8 & Contemporary education trends & 3
\end{tabular}

A data collection tool developed by the researcher in order to collect data was used in the research. Participants in the data collection tool were asked three questions below:

1. "Please explain the relationship between education and philosophy?"

2. "What are the benefits of the relationship between education and philosophy? Please explain."

3. "As an educational designer, which education philosophical trend would you choose if you wanted to make a new educational reform? Why? Please explain."

Content analysis methods used in qualitative pieces of research have been used in order to collect data gathered by means of data collection tools. Data analysis in qualitative research has three basic stages. The collected data is prepared and organized in the first step. The encoded data are minimized to themes and codes in the second stage. Tables and the analysis of the data minimized to themes and codes are presented with various figures, discussions, and interpretations in the last section (Güler, Halıcıoğlu and Taşğın, 2013). Thus, findings and results are achieved in the light of the data obtained in the study.

\section{Findings}

The quantitative and qualitative findings obtained from data collection tools used in the research are given separately.

\subsection{Qualitative Findings}

\subsubsection{Findings Related to Pretest Scores of Pre-Service Teachers}

At the beginning of the semester, the Educational Philosophy Course Learning Outcome Evaluation Test (EPCLOET) prepared by the researcher was applied to determine the preliminary knowledge of the students on the content of the educational philosophy course. The data on student scores from this test are given in Table 4. 
Table 4. Findings Related to Pretest Scores of Pre-Service Teachers from EPCLOET

\begin{tabular}{cccccccc}
\hline & Lowest Score & Highest Score & Mean & $\mathrm{N}$ & $\mathrm{S}$ & $\mathrm{t}$ & $\mathrm{sd}$ \\
\cline { 2 - 9 } Pre-test & 15.00 & 65.00 & 32.17 & 114 & 6.87 & .251 & 27 \\
\hline
\end{tabular}

When the data in Table 4 are examined, the findings about the pre-test scores of the students in the study group are found. It is seen that these students have pre-test scores $(\bar{X}=32,17)$.

\subsubsection{Findings Related to Post-Test Scores of Pre-Service Teachers}

At the beginning of the semester, the Educational Philosophy Course Learning Outcome Evaluation Test (EPCLOET) prepared by the researcher was applied to determine the preliminary knowledge of the students on the content of the educational philosophy course and the average scores of the students were found to be 32.17 . The contents of the subjects given in Table 2 were taught for eight weeks. After this time, EPCLOET has been applied again. Table 5 gives the data on student scores obtained as the result of the re-test.

Table 5. Findings Related to Post-Test Scores of Pre-Service Teachers from EPCLOET

\begin{tabular}{cccccccc}
\hline & Lowest Score & Highest Score & Mean & $\mathrm{N}$ & $\mathrm{S}$ & $\mathrm{t}$ & $\mathrm{sd}$ \\
\cline { 2 - 8 } Post-test & 50.00 & 90.00 & 83.2 & 114 & 8.87 & 0.201 & 28 \\
\hline
\end{tabular}

When the data in Table 4 are examined, the findings about the post-test scores of the students in the study group are found. It is seen that these students have post-test scores $(\bar{X}=83,2)$.

\subsection{Qualitative Findings}

\subsubsection{Findings Related to the First Question}

In the first question directed to pre-service teachers, they are asked to "explain the relationship between education and philosophy." When the answers given by the pre-service teachers about this relationship were examined, Table 6 has found.

Table 5. The Relationship between Education and Philosophy

\begin{tabular}{llll}
\hline & & $\mathrm{f}^{*}$ & $\%$ \\
\hline 1 & Being the human on the basis of both & 41 & 36.93 \\
2 & The holistic structure of philosophy & 18 & 16.21 \\
3 & Critical structure of philosophy & 17 & 15.31 \\
4 & The similarity of study subjects & 11 & 9.9 \\
5 & Being mutual obligation & 9 & 8.1 \\
6 & Philosophy is a tool for education & 9 & 8.1 \\
7 & Philosophy is the starting point of science & 6 & 5.4 \\
\hline$*(\mathrm{n}=111)$ & \multicolumn{3}{c}{}
\end{tabular}

According to Table 6, the opinions of pre-service teachers about the education and philosophy relationship are concentrated in seven different categories. 36.93\% of the pre-service teachers see "being of human on the basis of both philosophy and education" as the main reason of this relationship. According to the pre-service teachers $(16.21 \%)$ the "the holistic structure of the philosophy" is seen as the second most important relation source while the "the critical structure of the philosophy" constitutes the third order relation source by the pre-service teachers (15.31\%). However, "similarity of working areas" (9.9\%), "being a mutual obligation" (8.1\%), "philosophy is a tool for education" $(8.1 \%)$ and "philosophy is the starting point of science" $(5.4 \%)$ constitute other categories that pre-service teachers are seen as a source of relationship. Pre-service teachers have described the relationship between education and philosophy as in the examples below:

"... The object of education is human. Human is also the subject of philosophy. That's why the relationship between the two is human-focused. " (M11) 
“... Philosophy is in relation to all the phenomena. It develops considerations on education as well as every area that it is associated. It asks questions. It seeks answers. This is a relationship that arises from its holistic structure... " (F48)

“... Education and philosophy are intertwined. Education derives profit from philosophy, and philosophical education derives profit from education in the same way... " (M19)

“... Since ancient times science has been bound to science, education, and policy to philosophy. By the time it led away from the philosophy. The separation did not take it away. It strengthened the relationship between education and philosophy and formed the philosophy of education... "(F21)

“... Today, education is interdisciplinary. It deals with many science fields. Since these areas are also subject areas of philosophy, the relationship between them can be understood. So the subjects they are studying are common..." (M30)

\subsubsection{Findings Related to the Second Question}

In the second question directed to pre-service teachers, they are asked to explain "the benefits of the relationship of education and philosophy." When the answers given by the pre-service teachers about this relationship were examined, Table 7 has come to exist.

Table 7. The Benefits of the Relationship between Education and Philosophy

\begin{tabular}{llll}
\hline & Benefits & $\mathrm{f}^{*}$ & $\%$ \\
\hline 1 & Guiding the education & 22 & 19.81 \\
2 & Search for answers to educational problems & 16 & 14.41 \\
3 & Changing the point of view & 14 & 12.61 \\
4 & Analyzing education objectives & 11 & 9.9 \\
5 & Questioning the education system & 10 & 9.0 \\
6 & Questioning the teaching process & 10 & 9.0 \\
7 & Explaining concepts & 9 & 8.1 \\
8 & Providing formation of education programs & 8 & 7.2 \\
9 & Providing socialization of the individual & 8 & 7.2 \\
10 & Keeping education under control & 7 & 6.3 \\
11 & Determining needs & 7 & 6.3 \\
12 & Providing cultural transfer & 6 & 5.4 \\
13 & Building educational institutions & 4 & 3.6 \\
14 & Questioning human & 4 & 3.6 \\
15 & Providing development & 4 & 3.6 \\
\hline
\end{tabular}

*multiples answers for one participant

When Table 7 is examined, it is seen that pre-service teachers point out that the education-philosophy relationship has benefits in different dimensions. The most important benefit of this relationship has been "guiding the education" (19.81\%), which was most mentioned by pre-service teachers. "Search for answers to educational problems" appears to be the second benefit area $(14.41 \%)$, and "changing the point of view" as the third (12.61\%). Considering the views of pre-service teachers, it is seen that 15 different benefits are emphasized. Pre-service teachers expressed some of these benefits as follows:

"... The philosophy provides benefits in the inspection of the education system. Philosophy can inspect the educational system, students, and school structure by asking questions... " (F24)

“... Educational objectives can be more efficient in terms of functioning when they are handled in a philosophical way. Teaching can be successful if objectives are analyzed... " (F58) 
“... Educational philosophy helps to find answers to educational problems such as what will happen, what happened yesterday, today, tomorrow, how it happened, what kind of method-technique should be applied, what should be the course of proceeding, what is expected from an individual, what will happen in the future..." (M18)

“... Educational philosophy guides education by questioning the elements of education, its purpose, function and teaching methods... " (F71)

“... Philosophy contributes to the development of human. With the help of the objectives set for the education process, the culture of a society can be transferred to the individual. It helps the individual to understand his/her place in society... " (M9)

“... The questioning of the philosophy about education strengthens the education and gives it a new perspective... " (M30)

3.2.3 Findings Related to the Third Question

Pre-service teachers are posed the question, "Which educational philosophical trend you would choose if you wanted to make a new educational reform as an educational designer? Why? Please explain." The educational philosophical trends that pre-service teachers choose as answers are given in Table 8.

Table 8. Educational Philosophical Trends Preferred by Pre-Service Teachers

\begin{tabular}{llll}
\hline & & \multicolumn{1}{c}{$\mathrm{f}^{*}$} & \multicolumn{1}{c}{} \\
\hline Educational & Progressivism & 52 & 46.84 \\
Philosophical trends & Reconstructionism & 24 & 21.62 \\
& Essentialism & 11 & 9.9 \\
& Perennialism & 6 & 5.4 \\
Philosophical trends & Pragmatism & 12 & 10.81 \\
& Idealism & 3 & 2.7 \\
& Realism & 2 & 1.8 \\
Others & Mixed philosophy & 3 & 2.7 \\
\hline
\end{tabular}

$*(\mathrm{n}=111)$

According to Table 8, pre-service teachers have made preferences, including educational philosophical trends, philosophical trends and mixed philosophy. Among the educational philosophical trends, the "progressivism" trend (46.84\%) was most preferred by pre-service teachers. "Pragmatism" (10.81\%) from the philosophical trends stands out among pre-service teachers" preferences. Some pre-service teachers have needed to develop a "mixed" philosophical trend (2.7\%). Pre-service teachers expressed these preferences they made as follows:

"... I would choose "Reconstructionism" in the education reform that I would make. Because I think that the cultural crisis of the society that has been going on for centuries lies at the basis of the problems that are experienced in education. Individuals who are not in step with the society cannot create awareness in the society. For this reason, the values of the society should be reviewed again... "(F60)

“... If I wanted to make an educational reform, I would choose the "progressivism" trend. The teacher must constantly develop, get renewed and be ready for this. The teacher should be a guide in this trend. The main reason for me to choose this trend is the constant change and development of human, technology, and everything that can happen. While everything is developing and changing, education should not stay uniform, it must add meaningful learning to the bringing up generations... "(F8)

"... I would have taken the essentials trend. Those who do not know the past have difficulty building their future. The culture, tradition, and customs of the past must be transmitted to the new generation. We need an education that will not assimilate children within the modern culture and generations that are not unaware of their culture... "(M31)

“... I would choose realism. Because there are realities there. There are no changing judgments. The teacher knows what to teach to the student. I think that education will advance in a better way because there are realistic and non-subjective rules... "(F29) 
“... My educational reform involves a mixed philosophy. I would have taken the need of robustness both for characters and scientificness from perennialism, culturally appropriate objectives from essentialism, individual development and problem-solving from progressivism, and understanding of democracy and development of society from Reconstructionism. I would reflect on a mixed philosophy to the educational philosophy... "(K65)

Pre-service teachers have also explained the reasons for choosing educational philosophical trends they preferred above. Information on these views is given in Table 9.

Table 9. Reasons to Prefer Educational Philosophies of Pre-Service Teachers

\begin{tabular}{llcc}
\hline & Reasons for preference & f* $^{*}$ & $\%$ \\
\hline 1 & Being learner-centered & 31 & 27.92 \\
2 & Providing hands-on activities & 29 & 26.12 \\
3 & The individual is valued & 22 & 19.81 \\
4 & The importance of democratic life & 19 & 17.11 \\
5 & Human is free & 16 & 14.41 \\
6 & Solution to cultural crisis & 14 & 12.61 \\
7 & Problem-solving focus & 14 & 12.61 \\
8 & Aspiring to develop constantly & 12 & 10.81 \\
9 & Differing from real life & 11 & 9.9 \\
10 & Guidance of teacher & 9 & 8.1 \\
11 & Being social & 9 & 8.1 \\
12 & Helping to transfer culture & 9 & 8.1 \\
13 & Benefitting from knowledge & 8 & 7.2 \\
14 & Transfer of the past & 4 & 3.6 \\
15 & Having unchanging information & 4 & 3.6 \\
\hline
\end{tabular}

*multiples answers for one participant

According to Table 9, the reasons for choosing educational philosophical trends of pre-service teachers constitute 15 different categories. Moreover, it has been seen that there are multiple reasons which are effective for pre-service teachers to make a selection. From these reasons, the "being learner-centered" reason of the educational philosophical trend $(27.92 \%)$ is in the first place. While "providing hands-on activities" $(26.12 \%)$ reason becomes the second reason stated by pre-service teachers, "the individual is valuable" $(19.81 \%)$ reason forms the third most important reason affecting teachers' preferences. Some pre-service teachers have expressed the reasons for these preferences they have done in the following way:

Because:

"... it is needed that the changing social structure must not remain constant and always renew itself. The teacher is in the position of a guide. He/she should guide the student. He/she must have a sense of education that will gain problem-solving skills... "(M11)

"... education must be social. Society should be structured by education. Teacher and education are representatives of change..." (F25)

"... I think that some things should remain as essential. For example, religion and national values are sacred to us and should remain as they are. What is taught in the education system should not conflict with these sacred values... " (M3)

"... education must be student-centered. Active learning should be at the forefront. Students should learn by cooperating. The school should not prepare the child for life, school and life should be intertwined... " (F60)

"... we can overcome the cultural crisis, which is the biggest problem of our educational age, by redesigning society..." (F44) 
"... real and accurate information is the information that benefits the person. I agree with this view. As long as the information is beneficial to the individual and the society, it is the true information... "(F18)

\section{Conclusion}

This research was conducted in order to determine the perception of educational philosophy in the industrial age 4.0 and to find the educational philosophy productivity of pre-service teachers. 111 students who study in the 2nd class level and take the educational philosophy course have participated in the research. A test consisting of 25 questions, including educational philosophy course subjects was applied to these students as a pretest and post-test. After eight weeks of the teaching of the subjects, the students were tested again and the teaching success of the course was checked. In the pretest, the mean score of the class was calculated as 32.17. At the end of the post-test application after the teaching period, it was seen that the mean of the class reached the level of 83.2. It is possible to interpret this change, which is more than twice as high as the mean scores, as the success of teaching of educational philosophy course subjects.

Pre-service teachers have explained the relationship between education and philosophy in seven different categories. It has been concluded that pre-service teachers have expressed the philosophy and education relationship with human-based views. According to the pre-service teachers, the "the holistic structure of the philosophy" is seen as the second most important relation source while the "the critical structure of the philosophy" constitutes the third order relation source by the pre-service teachers. However, "similarity of working areas", "being a mutual obligation", "philosophy is a tool for education", and "philosophy is the starting point of science" constitute other categories that pre-service teachers are seen as a source of relationship.

According to the views of the pre-service teachers, the relationship between education and philosophy has been found to be beneficial in different dimensions. Pre-service teachers list the educational benefits of philosophy as follows:

$>$ Guiding the education,

$>$ Search for answers to educational problems,

$>$ Changing the point of view,

$>$ Analyzing education objectives,

$>$ Questioning the education system,

$>$ Questioning the teaching process,

$>$ Explaining concepts,

> Providing formation of education programs,

$>$ Providing socialization of the individual,

$>$ Keeping education under control,

$>$ Determining needs,

$>$ Providing cultural transfer,

$>$ Building educational institutions,

$>$ Questioning human,

$>$ Providing the development.

When pre-service teachers wanted to make a new educational design, it is found that they preferred in three different categories as educational philosophy, philosophy, and mixed philosophy. It has been concluded that almost half of the pre-service teachers participating in the study preferred mostly the "progressive" educational philosophy if they want to make a new educational design. Reconstructionism, essentialism, and perennialism constitute educational philosophy preferences of pre-service teachers respectively. Besides, pre-service teachers have expressed that they can develop a design with the help of philosophical trends other than educational philosophical trends. In this case, it has been determined that the philosophical trends they preferred were pragmatism, realism, and idealism. Apart from this, it has been seen that some pre-service teachers have created a mixed educational philosophy by using different trends. 
It has been seen that there are multiple reasons which are effective for pre-service teachers to make a selection. The reasons for choosing educational, philosophical trends of pre-service teachers have been found to constitute 15 different categories. For these reasons, the "being learner-centered" reason for the educational, philosophical trend is in the first place. While "providing hands-on activities" reason becomes the second reason stated by pre-service teachers, "the individual is valued" reason forms the third most important reason affecting teachers' preferences. This ordering can be interpreted as that they have appropriate ideas for contemporary education understanding. "The importance of democratic life" and "human is free" reasons of preference can be interpreted as that they attach importance to the freedom of individuals in the educational designs they want to make. "Solution to the cultural crisis", "being social" and "helping to transfer culture" reasons of preference suggest that pre-service teachers see the education as a tool in the reconstruction of society. "Problem-solving focused", "aspiring to develop constantly" and "Differing of real life" reasons can be interpreted as that the idea of the school must be the life itself rests in the education perception of the pre-service teachers. Besides, "transfer" of the past and "having unchanging information" reasons for preference point to the existence of those who have more conservative educational philosophy thoughts within the pre-service teachers. It has also been determined that pre-service teachers do not have a thought such as a requirement or expectation of a technological development in the educational process of industry age 4.0.

\section{Recommendations}

Pre-service teachers should not be deprived of the teaching of the educational philosophy course, as it is known that all elements of the educational process must be in need of a philosophy. Making the course more effective by increasing the teaching period will help to recognize the importance of the educational philosophy as needed.

It should not be forgotten that recognizing the meaning of trends of educational philosophy within educational activities by current studies will provide significant gains in educational reforms to be made. The idea that studies without a philosophy will not be built on sound grounds should be one of the basic disciplines of teacher education.

Designing an education program that does not have a full philosophy will be very difficult to succeed. For this reason, educational philosophy, which constitutes one of the foundations of the program development in education, needs to be actively and productively educated in the graduate programs. The teaching of the social, cultural, economic, psychological, political and philosophical foundations of the program development in education should be emphasized; different studies should be done especially in the context of educational philosophy.

Since it is found that the pre-service teachers who participated in this study are not in the expectation of a technological development related to the educational processes, education programs should be designed about technology and technology literacy with those that will raise awareness on this area in teacher education programs.

\section{References}

Bim-Bad, B., M., \& Egorova, L., İ. (2016). Interaction between philosophy of education and teaching practice. International Journal Of Environmental \& Science Education, 11(10), 3385-3393.

Creswell, J. W. (2003). Research Design: Qualitive and Quantitive Aproaches (2nd ed.). Thousand Oaks, CA: Sage.

Dash, S., N., R. (2015). Philosophical foundation of education. Directorate of Distance \& Continuing Education Utkal University, Vani Viharbhubaneswar-751 007.

Eldem, O., M. (2017). Endüstri 4.0. TMMOB EMO Ankara Şubesi Haber Bülteni. 2017(3), 10-16.

Ergün, M. (2015). Eğitim felsefesi. (5. Baskı). Ankara: Pegem Akademi.

Erkılıç, A., T., \& Himmetoğlu, B. (2015). Impacts of idealism on educational administration and classical management approaches. Anadolu Journal of Educational Sciences International, 5(2), 94-108. https://doi.org/10.18039/ajesi.85468

Güler, A., Halıcıoğlu, M. B., \& Taşğın, S. (2013). Sosyal bilimlerde nitel araştırma yöntemleri. Ankara: Seçkin.

Kopetz, H. (2011). Internet of Things. Real-time Systems. US: Springer. https://doi.org/10.1007/978-1-4419-8237-7_13

Krillov, N., P, Fadeeva, V., N., \& Fadeev, V., V. (2016). Modern philosophy of education. SHS Web Conferences 28, 01034(2016). https://doi.org/10.1051/shsconf/20162801034

Moore, T., W. (2010). Philosofy of education: An introduction. (Volume 14). Taylor \& Francis Group. London and New York. 
Schouten, G., \& Brighouse, H. (2015). The relationship between philosophy and evidence in education. Theory and Research in Education, 13(1), 5-22. https://doi.org/10.1177/1477878514562149

Schwab, K. (2016). The fourth industrial revolution. Geneva: World Economic Forum.

Stock, T., \& Seliger, G. (2016). Opportunities of Sustainable Manufacturing in Industry 4.0. Procedia CIRP, 40, 536-541. https://doi.org/10.1016/j.procir.2016.01.129

Tuncel, G. (2004). Öğretmenlerin kendi eğitim felsefelerini inşa etmeleri üzerine. Kazım Karabekir Eğitim Fakültesi Dergisi, 2004(10). 223-242.

TÜSİAD (2016). Türkiye'nin küresel rekabetçiliği için bir gereklilik olarak sanayi 4.0. Gelişmekte olan ekonomi perspektifi. TÜSİAD-T/2016-03/576. İstanbul.

Wiles, J. W., \& Bondi, J. C. (2011). Curriculum development (8th Ed.). Boston: Pearson. 